\title{
On Possible Impact of The Indian Summer Monsoon on the ENSO
}

\author{
B N Goswami and V Jayavelu \\ Center for Atmospheric and Oceanic Sciences, Indian Institute of Science, Bangalore 560012 , \\ India.
}

\begin{abstract}
The Indian summer monsoon (ISM) could influence the El Niño and Southern Oscillation (ENSO) only if it could induce significant surface wind anomalies in the active regions of central and eastern equatorial Pacific. Using 50-year NCEP reanalysis, it is shown that observed surface winds in the central and eastern Pacific associated 'purely' with ISM and unrelated to ENSO are very weak $\left(\sim 0.5 \mathrm{~m} . \mathrm{s}^{-1}\right)$. Strong surface winds in the central and eastern Pacific following a 'strong' or 'weak' ISM, noted in some earlier composite analyses, are related not to ISM but to the concurrent sea surface temperature (SST) forcing associated with the ENSO. A long run of an atmospheric general circulation model (AGCM) without inter-annual SST forcing also show that a 'pure' ISM induces only very weak surface winds in the equatorial central and eastern Pacific. Thus, we conclude that the ISM by itself is unlikely to influence the ENSO in a significant way.
\end{abstract}

\section{Introduction}

The correlation between the ISM and any indices of ENSO is strongest during the winter following the ISM (e.g.Yasunari 1990, 1991, hereafter referred to as Y12) indicating a possible active role of the ISM in modulating the ENSO. As such, the ENSO does not need the ISM for its existence as many coupled models (e.g. Zebiak and Cane, 1987) simulate a realistic ENSO without an active ISM through unstable air-sea interactions in the Pacific. However, the heat source variability associated with ISM could influence ENSO characteristics (the period, the amplitude, the episode duration etc.) through modification of surface stress in the Pacific. Some composite analysis (Y12) show that strong (weak) ISM are associated with significant easterly (westerly) surface wind anomalies in the central and eastern Pacific during the winter following the ISM. This observation strengthened the belief that the ISM plays an active role in modifying the ENSO characteristics. It must, however, be recongnised that many 'weak' or 'strong' phases of the ISM and 'warm' and 'cold' phases of the ENSO tend to occur simultaneously in nature. Large SST anomalies and surface wind anomalies in the Pacific are characteristically associated with the ENSO even without ISM. Therefore, the efficacy of the ISM in influencing the ENSO depends on its ability to induce significant surface wind anomalies in the active regions of central and eastern equatorial $\mathrm{Pa}$ cific in the absence of enhanced ENSO related SST forcing.

Copyright 2001 by the American Geophysical Union.

Paper number 2000GL011485.

0094-8276/01/2000GL011485\$05.00
Several recent studies (Yamagata and Matsumoto 1989, Wainer and Webster 1996, Chung and Nigam 1999, Kirtman and Shukla 1999, hereafter referred to as KS) have examined the possibility of modification of the ENSO characteristics by the ISM using simple coupled models. These studies show that if the ISM produces significant surface wind anomalies in the equatorial Pacific (as seen in the composites of Yasunari, 1990), it would indeed influence the ENSO in a perceptible way. All these studies except KS did not separate the ISM induced wind anomalies in the equatorial Pacific unrelated to simultaneous SST variability. KS used a 50-year long run of the COLA AGCM forced by climatological SST repeating every year to estimate the surface wind associated with intrinsic ISM variability. They find that the surface winds associated with their model monsoon have significant anomalies in the eastern equatorial Pacific. They further show that these stress anomalies once introduced in the Zebiak and Cane (1987) coupled model could intensify an ambient ENSO and even trigger a new one. To our knowledge, an estimate of equatorial surface winds in the Pacific associated with intrinsic ISM variability unrelated to SST forcing has not been made from observations so far. While the approach of KS is innovative and insightful, the realism of the Indian monsoon related stress anomalies in the Pacific simulated by their AGCM could not be tested. In the present study, our first objective is to estimate equatorial surface winds in the Pacific associated with intrinsic ISM variability unrelated to SST forcing from 50year observations (NCEP/NCAR reanalysis). In addition, ISM related equatorial surface winds in the Pacific are also estimated from a long run of another AGCM without any inter-annually varying SST forcing. Both observation and the AGCM simulations indicate that 'pure' ISM induced surface winds in the central and eastern Pacific are far too weak to induce significant influence on the ENSO.

\section{Data and Model Used}

Monthly mean circulation fields at several vertical levels for the period January 1949 to December 1998 were obtained from the NCEP/NCAR Reanalysis Project (Kalnay et al. 1996). The seasonal mean (June-September) all India monsoon rainfall (IMR) based on uniformly distributed rain gauge stations over continental India (Parthasarathy et al. 1994, updated for the recent years from publications of India Meteorological Department) is also used. The inter-annual variations are described by the anomalies from the long term mean of IMR. The Indian monsoon is considered 'strong' ('weak') if the normalized (by the inter-annual standard deviation) anomalies is $>+1(<-1)$. SST data for the period January 1949 to December 1991 have been obtained from the global analysis of SST created by Kaplan et al. (1997). 


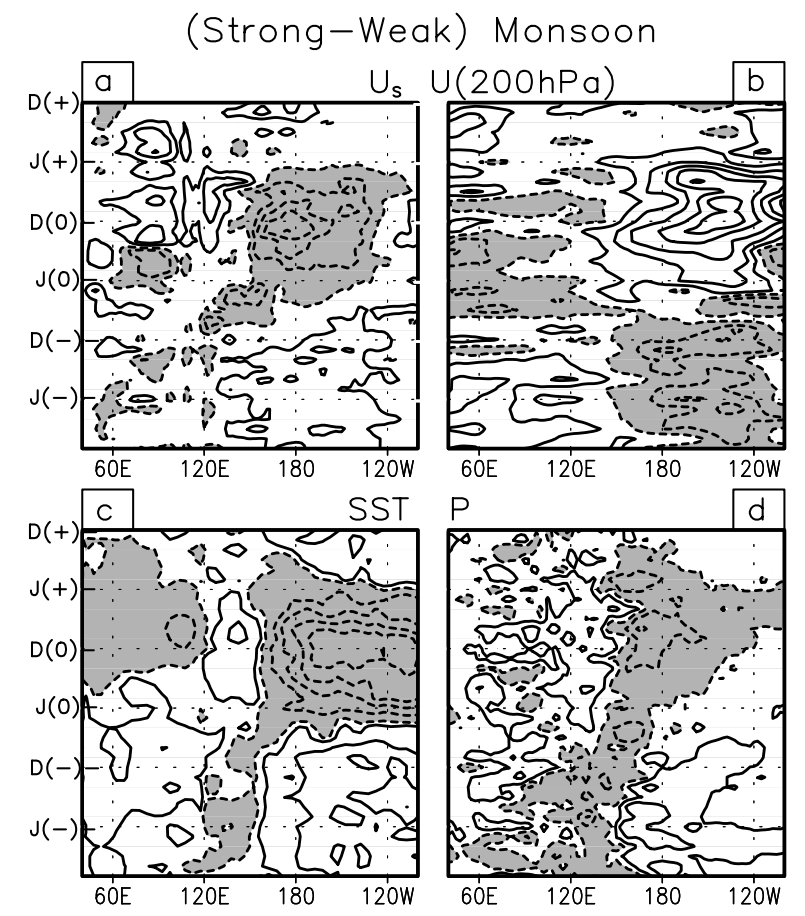

Figure 1. Equatorial cross section $\left(5^{\circ} \mathrm{S}-5^{\circ} \mathrm{N}\right)$ of composite difference between 'strong' and 'weak' monsoons. (a) Surface zonal winds $\left(\mathrm{U}_{\mathrm{s}}\right)$ with, minimum contours (MC's) are $\pm 0.3 \mathrm{~m} . \mathrm{s}^{-1}$ and contour intervals (CI's) are $0.5 \mathrm{~m} . \mathrm{s}^{-1}$ and $0.2 \mathrm{~m} . \mathrm{s}^{-1}$ respectively. Zonal winds (b)at $200 \mathrm{hPa}, \mathrm{MC}$ 's are $\pm 1.0 \mathrm{~m} . \mathrm{s}^{-1}$, CI is 2.0 $\mathrm{m} . \mathrm{s}^{-1}$. (c) SST, MC's are $\pm 0.1{ }^{\circ} \mathrm{C}$, CI is $0.4{ }^{\circ} \mathrm{C}$. (d) Precipitation, MC's are \pm 1.0 mm.day ${ }^{-1}$, CI is 3.0 mm.day ${ }^{-1}$. The negative contours are shaded. The zero-lag corresponds to the summer of the 'strong' or 'weak' monsoon and is centered around July.

For the recent years we have added the Optimum Interpolation SST (OISST) data set (Reynolds and Smith 1994). We also use the monthly precipitation analysis created by Xie and Arkin (1996) covering the period January 1979 to December 1998. Table 1 lists 'strong' and 'weak' monsoon years selected following the criterion described above and $\mathrm{El}$ Niño and La Niña years based on Nino3 (150W-90W,5S-5N) SST anomalies together with a list of 'non-ENSO' 'strong' and 'weak' monsoon years. In choosing 'non-ENSO' monsoon years, the criterion of $>1$ s.d (or $<-1$ s.d) was relaxed to $>0.5$ s.d (or $<-0.5$ s.d).

Table 1. Years used as the 'zero years' in different composites.

\begin{tabular}{crrrrr}
\hline \multicolumn{2}{c}{ Monsoon } & \multicolumn{2}{c}{ Non-ENSO } & \multicolumn{2}{c}{ Non Monsoon } \\
Strong & Weak & Strong & Weak & El Niño & La Niña \\
\hline 1956 & 1951 & 1953 & 1968 & 1957 & 1949 \\
1959 & 1965 & 1959 & 1974 & 1963 & 1954 \\
1961 & 1966 & 1961 & 1979 & 1976 & 1973 \\
1970 & 1968 & 1994 & 1985 & 1997 & 1978 \\
1975 & 1972 & & & & \\
1983 & 1974 & & & & \\
1988 & 1979 & & & & \\
1994 & 1982 & & & & \\
& 1986 & & & & \\
& 1987 & & & & \\
\hline
\end{tabular}

The atmospheric model used in this study is a version of the Geophysical Fluid Dynamics Laboratory (GFDL) climate model. This version has rhomboidal 30 horizontal resolution and 14 unevenly placed sigma levels in the vertical. The details of the model and the physical parameterizations used are described in some detail in Goswami (1998) and it was shown that the AGCM simulates the ISM with an acceptable degree of fidelity. A long run of the model was carried out in which climatological seasonal cycle of global SST and sea ice were prescribed and repeated every year. The last 20 years of a 40 year run is used here.

\section{Results and Discussions}

To bring out the changes in the equatorial circulation associated with ISM, difference between 'strong' and 'weak' monsoon lead-lag composites of zonal winds at surface and $200 \mathrm{hPa}$, SST and precipitation are constructed (Fig. 1). Zonal winds anomalies at $850 \mathrm{hPa}$ are similar to those at surface but stronger by nearly a factor of two. Similar to the findings of previous studies (Y12), the surface zonal wind composites show significant easterly anomalies in the central and eastern Pacific during winter and spring following a 'strong' summer monsoon. We note that, positive SST anomalies that prevail in the equatorial Indian Ocean prior to a strong Indian summer monsoon, appear to move eastward to the western Pacific and establish as a strong positive SST anomaly by the end of the 'strong' monsoon season. This movement of the warm waters is associated with eastward movement of the enhanced precipitation zone to the western Pacific. The zonal wind anomalies at surface are consistent with response of the atmosphere to the associated heating (easterly anomalies to the east and westerlies to the west of the heating). The upper level winds are nearly opposite to those at lower level and consistent with a first baroclinic response to the heat source. Thus, there appears to be a coherent coupled evolution of the equatorial circulation associated with the Indian monsoon. It is rather interesting to note that the anomalies of SST and low and upper level winds are largest not over the Indian Ocean or western Pacific but in the central and eastern Pacific.

From Table 1, we note that many 'strong' or 'weak' monsoons are associated with La Niña or El Niño respectively.

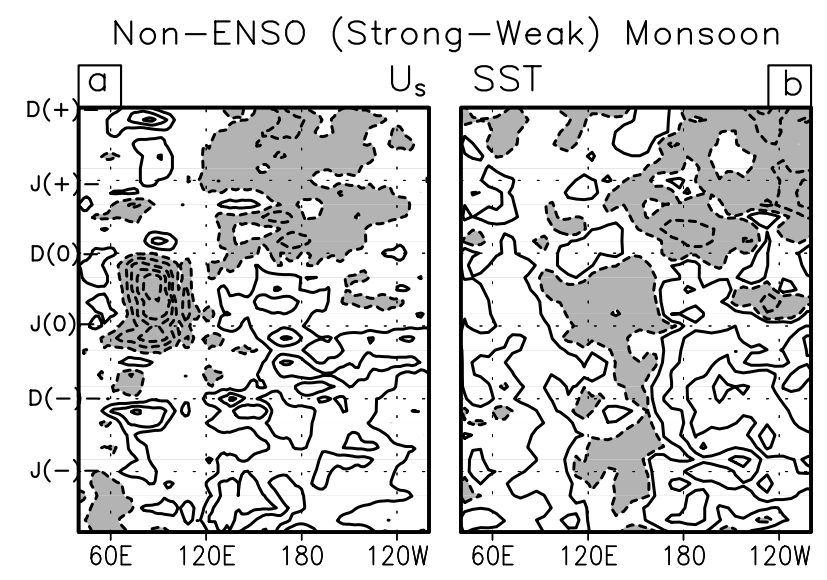

Figure 2. Same as Fig. 1 except for 'strong' and 'weak' years that were not related to La Niña or El Niño (Table 1). Composite of only surface wind $\left(\mathrm{U}_{\mathrm{s}}\right)$ and SST are shown. 


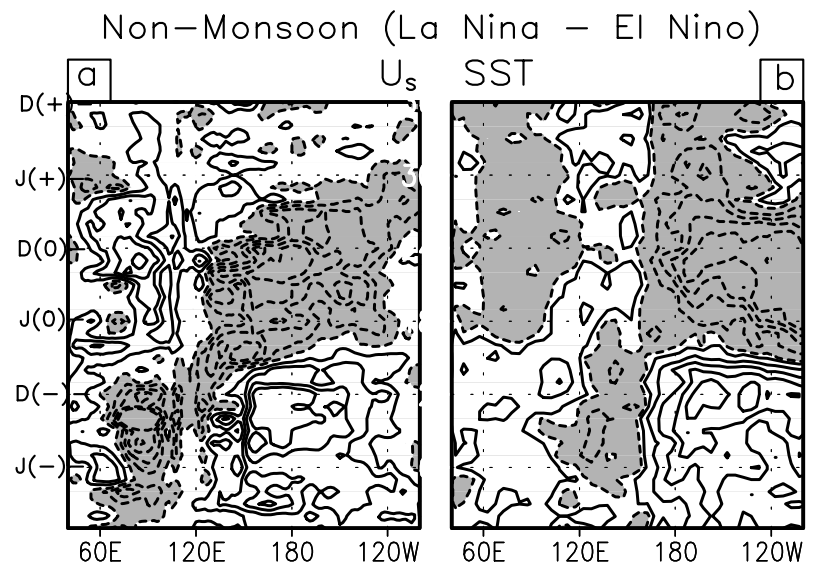

Figure 3. Same as Fig. 2 except for La Niña minus El Niño years unrelated to ISM.

Therefore, part of the wind anomalies in the equatorial $\mathrm{Pa}-$ cific could have come from the SST induced precipitation forcing associated with the ENSO events. To get an estimate of wind anomalies associated only with the ISM, we construct composite of 'strong' and 'weak' monsoons that are not related to ENSO. From the 50-year period of NCEP/NCAR reanalysis, we have been able to get four such cases each of 'strong' and 'weak' monsoon years. Fig. 2 shows that the surface wind and SST anomalies throughout the equatorial Pacific associated with a 'pure' Indian monsoon tend to be very weak. In contrast to the anomalies in Fig. 1, where maximum zonal wind anomalies at surface in the central and eastern Pacific goes up to $2.3 \mathrm{~m} . \mathrm{s}^{-1}$, it goes up to only $0.8 \mathrm{~m} . \mathrm{s}^{-1}$ without the ENSO influence. Further, the surface zonal winds following a 'pure' strong (weak) ISM remains westerly (easterly) till December/January unlike strong easterly (westerly) during the same period in Fig. 1. We also examined the composite of La Niña minus El Niño years that were not associated with 'strong' and 'weak' monsoons (Fig. 3). The anomalies in Fig. 1 could be reproduced almost fully by superposition of anomalies in Figs. 2 and 3. A comparison of Figs. 1 and 3 clearly shows that the large surface and low-level wind anomalies in the central Pacific seen the monsoon composite arise due to simultaneous ENSO related heating in the Pacific.

To obtain an independent estimate of 'pure' ISM induced winds in the equatorial Pacific, a long simulation of the GFDL AGCM forced by climatological SST is examined. We define Indian monsoon rainfall (IMR) as simulated precipitation averaged over $60^{\circ} \mathrm{E}-100^{\circ} \mathrm{E}$ and $10^{\circ} \mathrm{N}-30^{\circ} \mathrm{N}$. The simulated seasonal mean (June-September) anomalies of IMR for the 20-year period are shown in Fig. 4(a). The standard deviation of the model internal IMR (0.53 mm.day $\left.{ }^{-1}\right)$ is comparable to the observed one $\left(0.72 \mathrm{~mm}^{-d a y}{ }^{-1}\right)$. The regression of simulated zonal stress on the model IMR index is shown in Fig. 4(b) and represents circulation variability associated with the Indian monsoon. The zonal surface stress anomalies have familiar character in the Indian Ocean, 'strong' ('weak') monsoons being associated with westerly (easterly) stress between equator and $15^{\circ} \mathrm{N}$ and easterly (westerly) stress north of it. However, unlike KS, conspicuous by its absence are the easterly anomalies in the equatorial eastern Pacific. In fact, throughout the equa- torial Pacific, the easterly stress anomalies associated with the Indian monsoon are quite weak. The largest easterly anomalies in the eastern Pacific occurs not around the equator but north of $10^{\circ} \mathrm{N}$. While the GFDL AGCM may have its own share of systematic errors, the similarity between the 'pure' ISM related winds in the equatorial Pacific simulated by the AGCM and those obtained from observation (non-ENSO ISM composites, Fig. 2) provides confidence in the AGCM results.

\section{Conclusions}

In this study, we have tried to un-tangle the influence of the Indian monsoon and that of the ENSO SST forcing on surface winds in the equatorial Pacific. The 50year NCEP/NCAR reanalysis provides a sufficiently long homogeneous data set to try to separate the influence of the Indian monsoon from that of the ENSO itself. Composites of 'strong' and 'weak' monsoons unrelated to ENSO clearly show that the Indian monsoon, by itself, does not produce significant surface wind anomalies in the equatorial Pacific either during or following the monsoon season. Maximum zonal surface stress anomalies are of the order of 0.01 dynes.cm ${ }^{-2}$. These weak surface wind anomalies are consistent with the fact the precipitation anomalies associated with the Indian monsoon alone do not extend beyond about $160^{\circ} \mathrm{E}$. It is also shown that the large surface wind anomalies in the central and eastern Pacific associated with strong (weak) ISM are essentially due to the SST anomalies associated with El Niño and La Niña.

This finding is further tested using an AGCM. The internal monsoon variability of amplitude comparable to those

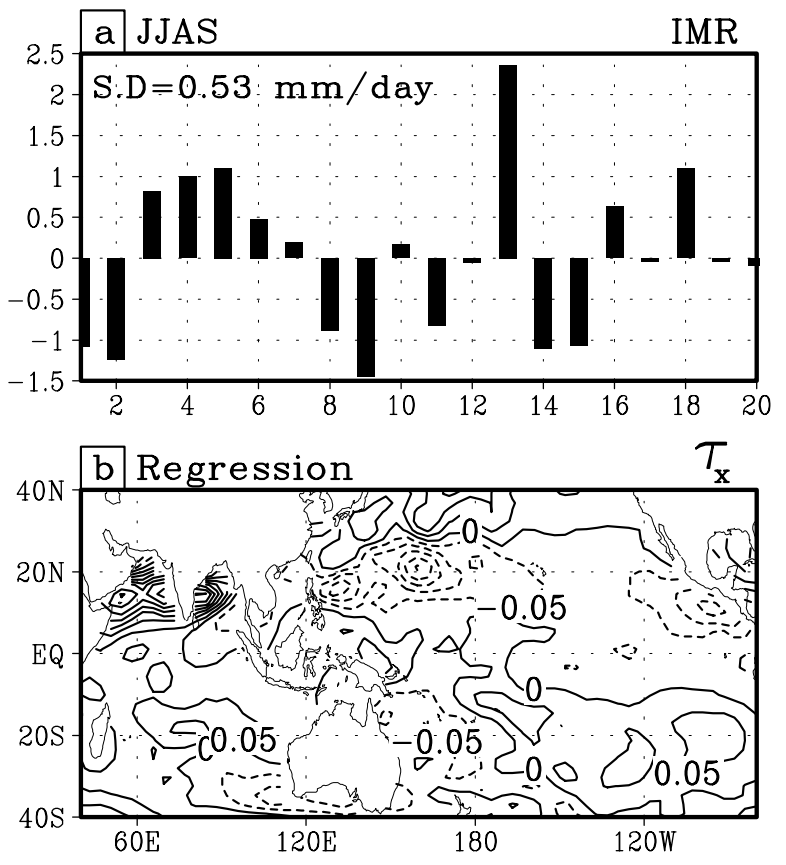

Figure 4. (a) Normalized simulated seasonal mean (JuneSeptember) monsoon anomalies. (b) Regression of simulated zonal stress on the model IMR, scaled to show the zonal stress anomalies (dynes.cm ${ }^{-2}$ ) associated with a variation of 2 mm.day ${ }^{-1}$ change in the model IMR. CI is 0.05 dynes.cm ${ }^{-2}$, negative contours are dashed lines. 
observed is simulated in a long run without any inter-annual SST forcing. Regression pattern of the surface stress on simulated Indian monsoon index show very weak surface zonal stress anomalies in the equatorial Pacific associated with a pure Indian monsoon. The magnitude of small zonal stress anomalies along the equatorial belt is comparable to those estimated from observations. Like observations, the AGCM also indicates that the reason for the weak equatorial zonal stress anomalies associated with the Indian monsoon is related to the fact that the rainfall anomalies associated with a 'pure' Indian monsoon do not tend to extend eastward of $160^{\circ} \mathrm{E}$. A linear model forced with the precipitation anomalies associated with our various composites (Figures not shown) support the above conclusion. These results indicate that, the Indian monsoon is unlikely to introduce significant wind response in the central and eastern Pacific and hence unlikely to influence the ENSO related air-sea interactions in a significant way. It could, however, introduce a stochastic component in the ENSO system and could influence the periodicity (Wainer and Webster 1996). Some past studies may have arrived at erroneous conclusions as the response of the Indian monsoon was not separated from that of the ENSO SST.

Acknowledgments. This work is partially supported by a grant from the Department of Science and Technology, Government of India.

\section{References}

Bassnett, T. A., and D. E. Parker, Development of global sea level pressure data set GMSLP2, Climate Research Technical Note 79, 54pp (Available from Hadley Center, Meteorological Office, London Road, Bracknell, Berkshire, RG1225Y, UK), 1977.

Chung C. and S. Nigam, Asian summer monsoon-ENSO feedback on the Cane-Zebiak model ENSO, J. Climate, 12, 2787-2807, 1999.
Goswami, B. N., Inter-annual variations of Indian summer monsoon in a GCM: External conditions versus internal feedbacks, J. Climate, 11, 501-522, 1998.

Kalnay, E. et al., The NCEP/NCAR 40 year Reanalysis Project, Bull. Am. Meteor. Soc., 77, 437-471, 1996.

Kaplan, A., Y. Kushnir, M. A. Cane, and M. B. Blumenthal, Reduced space optimal analysis for historical data sets: 136 years Atlantic sea surface temperatures, J. Geophys. Res., 102C, 27,835-27,860, 1997.

Kirtman, B. P. and J. Shukla, Influence of the Indian summer monsoon on ENSO, Q. J. Roy. Meteor. Soc., 126, 213-239, 1997.

Parthasarathy, B., A. A. Munot, and D. R. Kothawale, All India monthly and seasonal rainfall series: 1871-1993, Theor. Appl. Climatol., 49, 217-224, 1994.

Reynolds, R. W., and T. M. Smith, Improved global sea surface temperature analysis using optimum interpolation, J. Climate, 7, 929-948, 1994.

Wainer, I. and P. J. Webster, Monsoon/El Niño-Southern Oscillation relationships in a simple coupled ocean-atmosphere model, J. Geophys. Res., 101C, 25,599-25,614, 1996.

Xie, P. P., and P. A. Arkin, Analysis of global monthly precipitation using gauge observation, satellite estimates, and numerical model prediction, J. Climate, 9, 840-858, 1996.

Yamagata, T. and Y. Matsumoto, A simple ocean-atmosphere coupled model for a warm El Niño Southern Oscillation event, Phil. Trans. Roy. Soc. London., A329, 225-236, 1989.

Yasunari, T., Impact of Indian monsoon on the coupled atmosphere/ocean system in the tropical Pacific, Meteorl. Atmos. Phys., 44, 29-41, 1990.

Yasunari, T., The monsoon year- A new concept of the climate year in the tropics, Bull. Am. Meteorol. Soc., 72, 1331-1338, 1991.

Zebiak, S. E., and Cane, M.A., A model ENSO, Mon. Weather Rev., 115, 2262-2278, 1987.

B N Goswami and V Jayavelu, Center for Atmospheric and Oceanic Sciences, Indian Institute of Science, Bangalore 560 012, INDIA. (e-mail: goswamy@caos.iisc.ernet.in)

(Received February 7, 2000; accepted July 10, 2000.) 